\title{
Further experiments on habit reversal in the fish '
}

\author{
ERIKA R. BEHREND AND M. E. BITTERMAH
}

BRYN MAWR COLLEGE

Progressive improvement in habit reversal was sought without success under conditions in which two previous experiments with the fish had led us to expect that it might appear.

In the first experiment on reversal learning in the fish, animals trained to criterion in each of a series of visual reversals gave some indication of progressive improvement, especially when the noncorrection method was used (Wodinsky \& Bitterman, 1957). Although subsequent failures to find the effect under a variety of conditions led us to discount the earlier results as an artifact of poor technique (Bitterman, Wodinsky, \& Candland, 1958; Behrend, Domesick, \& Bitterman, 1965), the noncorrection method was not subsequently used. We report here an experiment (patterned after the first) which was designed to examine the possibility that the noncorrection method, by maximizing negative transfer in early reversals, provides more opportunity for improvement than do other methods.

Progressive improvement appeared again in a recent experiment by Setterington \& Bishop (1967). Theirs was a spatial problem, their animals were trained in daily 20-trial sessions with the correct position reversed after each session, and they used the method of unlimited correction. The difference between their results and previous (negative) results with spatial problems may be due, they suggested, to the greater spatial separation of their targets, or to their use of unlimited correction, or to sampling error. We report here an attempt to replicate their results.

Method

Goldfish were trained to discriminate between red and green in daily 40-trial sessions to a criterion of no more than six errors per session and no more than three errors in the last 20 trials of the session. Of the 16 (4-5 in.) Ss, eight then were trained in a series of 10 successive reversals, each to the same criterion. The remaining eight Ss had three sessions of overtraining after reaching criterion in each of the 11 problems. The fully automated apparatus was the same as that used by Behrend, Domesick, \& Bitterman (1965) and described in detail by Bitterman (1966). Each trial began after an intertrial interval in darkness with the illumination of the targets with red and green lights, the position of the two colors varying randomly from trial to trial. The noncorrection method was used. Each incorrect response was followed by an intertrial interval in darkness. Each correct response was followed by reinforcement (target-lights off, feederlight on) and then by an intertrial interval in darkness.

For a series of 8020 -trial daily spatial reversals, six 3-in. African mouthbreeders were selected. The standard apparatus was used, but instead of the regular targets (1-1/4 in. in diameter and 2-1/2 in. apart) we used targets like those of Setterington and Bishop (1/4 in. in diameter and 3-1/2 in. apart). Our targets were not removed from the water after each response (as were those of Setterington \& Bishop), but remained in the water with their (white) lights turned off. Unlimited correction was used. Each incorrect response was followed by a 2-sec timeout in darkness, after which the targets were illuminated again. Each incorrect response was followed by a reinforcement (target-lights off, feeder-light on) and then by a 6-sec intertrial interval in darkness.

Resulis

In Fig. 1 the results of the noncorrection experiment are plotted in terms of mean errors to criterion in the original problem and in each of the 10 subsequent reversals. It seems clear that overtraining produced more negative transfer to begin with than did criterion training alone, but there was no improvement in either group. Analysis of variance shows no significant Groups effect $(F<1)$, no significant Reversals effect $(F=1.28$, df $=9 / 126, p>.05$ ), but a significant interaction of Groups by Reversals ( $F=2.18, d f=9 / 126, p<.05)$.

The results of our correction experiment are compared with those of Setterington and Bishop in Fig. 2, where within-reversals curves plotted in terms of initial errors per block of five trials are pooled for successive blocks of 20 reversals. Our curves are much steeper than those of Setterington and Bishop (that is, they show better within-reversals learning), but they give no indication of improvement over reversals. Analysis of variance shows a significant Trials

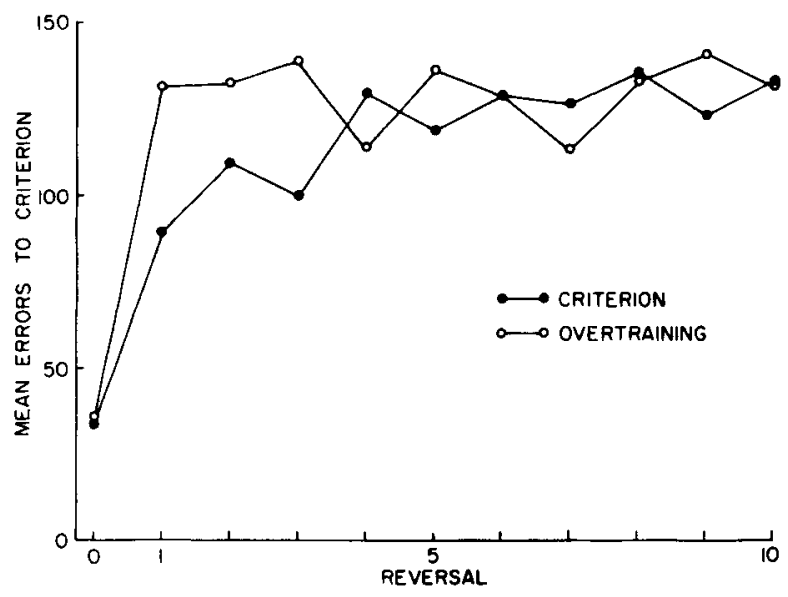

Fig. 1. Mean errors to criterion in an original red-green discrimination and a series of 10 reversals. One group was trained to criterion in each problem and the second was overtrained. 


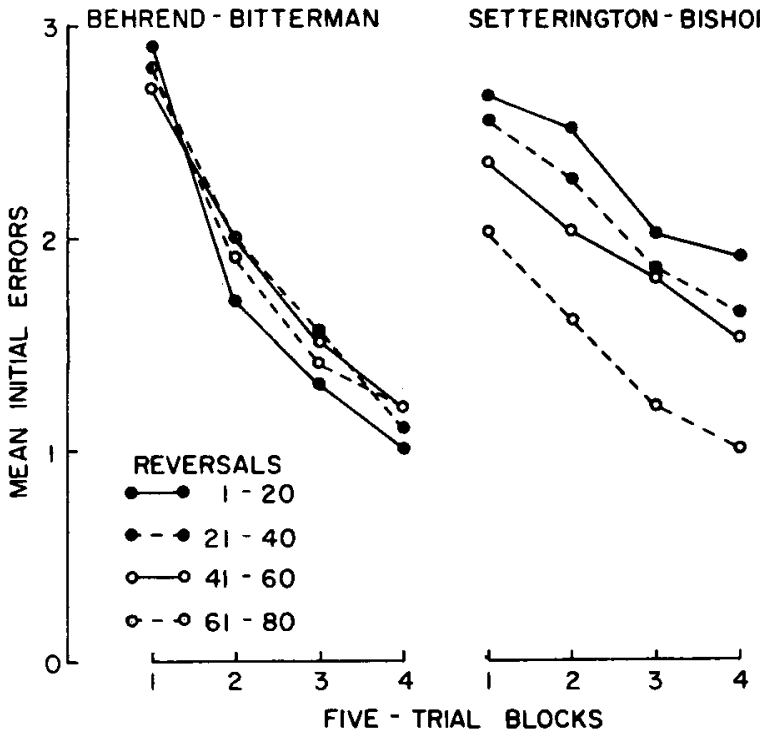

Fig. 2. Pooled within-reversals learning curves for the animals of the present experiment which were trained in 20-trial spatial problems and for the animals of Setterington and Bishop (1967).

effect $(F=84.49$, df $=3 / 15, p<.01$ ), but neither a significant Reversals effect $(F<1)$ nor a significant interaction ( $F<1$ ). Like Setterington and Bishop, however, we did find significant improvement in repetitive errors over reversals. Analysis of variance shows a significant Trials effect ( $F=48.09, \mathrm{df}=3 / 15, p<.01$ ), a significant Reversals effect $(F=4.42, \mathrm{df}=3 / 15, \mathrm{p}<.05)$, and a significant interaction ( $F=7.13, d f=9 / 45, p<.01$ ). The interaction reflects the fact that the improvement in repetitive errors over reversals occurred largely in the first block of five trials.

Discussion

Both the Wodinsky results and the Setterington results which we here attempted to replicate were obtained by techniques which involved the manual introduction of the targets before each choice rather than the illumination of targets already in the water, and it is tempting to assign some importance to the difference. The manual procedure might improve performance in the same way that a gap to be jumped, or some other method of producing a pause before choice, improves the discriminative performance of rats. In fact, however, the within-reversals performance of our correction animals was considerably better than the performance of Setterington's animals. Another possibility is that the manual procedure is more susceptible to the influence of experimentervariables. It should be noted, of course, that other experiments with the manual procedure have failed to yield progressive improvement in the fish (Bitterman, Wodinsky, \& Candland, 1958).

The difference between our correction results and Setterington's may be due to a difference in intertrial interval. We designed our experiment on the basis of information contained in a letter from Setterington which made it clear that he had used a 2-sec timeout after error but which gave us the impression that his intertrial interval was, not 2 sec (as the published paper specifies), but 10-15 sec. Accordingly, we used a 4-sec feeder light followed by a 6-sec interval in darkness after each correct response. The fact that our animals showed progressive improvement in repetitive errors but not in initial errors suggests that the interval between successive responses may be an important variable. Setterington's finding (personal communication) that short timeouts maximize improvement in repetitive errors indicates that such improvement may be based on sensory carryover or some short-term memory mechanism. If a short intertrial interval favors a winstay pattern in the same way as a short timeout may be assumed to favor a lose-shift pattern, then short intertrial intervals should maximize improvement in initial errors. A replication of the Setterington result for initial errors with a short intertrial interval would not, of course, detract from the validity of the conclusion that the habit-reversal technique reflects the operation of different learning mechanisms in fish and rat. References

Behrend, E. R., Domesick, V. B., \& Bitterman, M. E. Habit reversal in the fish. J. comp. physiol. Psychol., 1965, 60, 407-411.

Bitterman, M. E. Animal learning. In J. Sidowski (Ed.), Experimental methods and instrumentation in psychology. New York: McGraw-Hill, 1966. Pp. 451-484.

Bitteman, M. E., Wodinsky, J., \& Candland, D. K. Some comparative psychology. Amer. J. Psychol., 1958, 71, 94-110.

Setterington, R. G., \& Bishop, H. E. Habit reversal improvement in the fish. Psychon. Sci., 1967, 7, 41-42.

Wodinsky, J., \& Bitterman, M. E. Discrimination-reversal in the fish. Amer. J. Psychol., 1957, 569-576.

\section{Note}

1. This research was supported by Grant MH-02857 from the U. S. Public Health Service. The assistance of Miss Joy Quill is acknowledged with thanks. 